\title{
O ENLACE ENTRE GÊNERO, ETNIA E CLASSE SOCIAL
}

\section{Angela Maria Moura Costa Prates ${ }^{1}$ \\ Dienifer Aparecida Lopes²}

Resumo: $\bigcirc$ objetivo deste artigo é analisar as conexões entre gênero, etnia e classe social, seus reflexos e contribuições para a desigualdade entre homens e mulheres. Na metodologia foi utilizada a revisão de literatura e pesquisa documental, bem como uma abordagem qualitativa e quantitativa. Apresentou-se uma discussão teórica das categorias gênero, classe social e etnia. Em seguida, há uma discussão sobre os papéis sociais, demonstrando, através dos dados coletados, a desigualdade de gênero e sua interface com etnia e classe social. Assim, percebeu-se que as categorias gênero, etnia e classe social juntas influenciam as escolhas, decisões e a posição social das mulheres na sociedade.

Palavras-chave: Gênero; etnia; classe social.

Abstract: This paper analyzes the relation between gender, ethnic and social class, its reflections and contributions for inequality between men and women. For the methodology, a literature review and documentary research was conducted under a qualitative and quantitative approach. The categories gender, social class and ethnicity are discussed together with social roles, and gender inequality and its interface towards ethnic and social class is also presented. The results show that these categories in conjunction influence the choices, decisions and social position of women in society.

Keywords: Gender; ethnic; social class.

\section{Introdução}

As relações de gênero pautam-se numa herança do sistema patriarcal, que é baseado em uma cultura machista e sexista que perpassa historicamente a sociedade, reafirmando o posicionamento de dominação masculina e submissão feminina. Nesse contexto, este artigo tem como objetivo

\footnotetext{
1 Doutora em Serviço Social, Universidade Estadual do Centro-Oeste, Brasil. E-mail: pratesammc@gmail.com. Orcid: 0000-0003-0594-6463

2 Graduanda em Serviço Social, Universidade Estadual do Centro-Oeste, Brasil. E-mail: dheny_lopes@live.com. Orcid: 0000-0002-9450-3607
} 
analisar as conexões entre gênero, etnia e classe social e seus reflexos e contribuições para a desigualdade entre homens e mulheres.

Como procedimento metodológico utilizamos uma abordagem qualitativa e quantitativa, entendendo que ambas são complementares (MARTINELLI, 1999). Utiliza-se também a revisão de literatura e de pesquisa documental para mostrar a desigualdade de gênero e sua relação com etnia e classe social.

Nesse sentido, discutem-se as categorias gênero, etnia e classe social, que se desenvolvem ao longo da história, e quais particularidades elas apresentam em cada momento. Desmistificam-se, assim, os papéis sociais culturalmente atribuídos a homens e mulheres. Compreende-se a desigualdade de gênero e sua interface com etnia e classe social através dos dados coletados e, a partir disso, elencam-se como categorias de análise o modelo familiar, domicílios chefiados por mulheres, cursos superiores com maior e menor prestígio social, acesso à educação, mercado de trabalho e violência.

\section{Gênero, etnia e classe social}

A população brasileira foi colonizada por uma elite branca que tentou de todas as maneiras impor sua cultura como dominante, explorando não somente as riquezas desta terra, como também seus habitantes nativos, depois os negros que aqui chegaram, trazidos de África apinhados em navios negreiros, e mais tarde imigrantes de diversos países. É importante salientar que os negros foram arrancados de suas terras, de suas famílias, escravizados e brutalmente violentados. Suas crenças e costumes foram desprezados e menosprezados. Uma consequência disso é o preconceito racial que a população negra sofre diariamente no Brasil (SILVA, 2014).

Durante o período da escravidão, homens e mulheres nessa condição sofriam praticamente os mesmos castigos, com a diferença de que as mulheres, além de chicoteamentos e punições, sofriam também a violência sexual, que era uma prática constante. As escravas eram vistas como objeto de satisfação sexual dos seus senhores, pois a "violação era uma arma de dominação, uma arma de repressão, cujo maior objetivo era extinguir a vontade das mulheres escravas em resistir, e nesse processo, desmoralizar os seus homens" (DAVIS, 2013, p. 25). Pode-se perceber que durante - período da escravidão os papéis delimitados para homens e mulheres variam de acordo com a cor da sua pele. À mulher branca é destinado o papel de esposa e mãe, ocupada com os cuidados da casa e o bem-estar dos 
seus. Não lhe é permitido o prazer, pois o sexo para elas é apenas um meio para a garantia de herdeiros e a continuidade do nome da família. Para o prazer os senhores usavam as escravas, com as quais tudo era permitido. As mulheres negras eram vistas como promíscuas e imorais, e nem o papel de mãe thes era permitido. Conforme Davis (2013, p. 12), "aos olhos dos donos de escravos, as mulheres escravas não eram mães em absoluto; eram simplesmente instrumentos que garantiam o crescimento da força de trabalho escravo".

A escravidão chegou ao fim no século XIX, mas a desigualdade imposta pela cor da pele não. Os negros recém-libertos passaram por muitas dificuldades e enfrentaram todas as formas de preconceito. Sem qualificação e alfabetização era muito difícil encontrar um emprego. Vale lembrar que o acesso à educação foi uma conquista que aconteceu muito tempo depois e graças a muita luta.

Diante disso, foram destinados aos negros trabalhos inferiores, com remunerações baixas; aos homens o trabalho com a terra, às mulheres o trabalho doméstico. A mulher negra desempenha uma dupla função, pois acumula também o papel de mãe, esposa e dona de casa naturalmente atribuído ao gênero feminino. Em prol da sua sobrevivência, enfrenta há muito tempo o mercado de trabalho, com jornadas exaustivas e mal remuneradas, sendo exploradas de maneira mais intensa que os homens. "As mulheres negras raramente se esforçavam para serem fracas; elas tinham de se transformar em fortes, para as suas familias e comunidades que precisavam da sua força para sobreviver" (DAVIS, 2013, p. 164). Nem a fragilidade, naturalmente associada ao gênero feminino, era-lhes permitida. A mulher negra aprendeu, desde cedo, que precisava ser forte e enfrentar todas as adversidades com coragem, pois lutava em benefício próprio e, principalmente, por seus filhos, sua família, sua raça. Em uma sociedade onde as posições sociais são delimitadas de acordo com a raça e a classe social à qual pertencem, as mulheres pobres precisavam se unir.

[...] como as suas irmãs brancas chamadas "donas de casa", elas cozinharam e limparam e foram cuidadoras e criaram um incontável número de crianças. Mas ao contrário das suas irmãs brancas, que dependiam do seu marido para a segurança econômica, às mulheres negras e mães, habitualmente trabalhadoras, raramente foi-lhes dado o tempo e a energia para serem peritas em domesticidade. (DAVIS, 2013, p. 164). 
Percebe-se aqui que o papel da mulher é delimitado não apenas pela sua etnia, mas também pela classe social à qual pertence. As mulheres brancas e burguesas eram consideradas eximias donas de casa. Sua dedicação era exclusiva aos cuidados com a família. Não carregavam o duplo fardo de serem mães, esposas e ainda lutar pela sobrevivência dos seus, pois a obrigação de prover o sustento do lar era do marido. A luta pela independência financeira e pelo acesso ao mercado de trabalho para essas mulheres aconteceu somente muito tempo depois. $\bigcirc$ mesmo não se passa com as mulheres que vivem em situação de pobreza. Em uma sociedade tão desigual, onde o que se ganha com o trabalho é suficiente apenas para a subsistência, não lhes é permitido ser apenas uma dona de casa.

Há muito tempo essas mulheres enfrentam o mercado de trabalho, com jornadas exaustivas, sendo exploradas de todas as formas, visto que para elas são destinados os trabalhos considerados inferiores e com baixas remunerações. Ao retornar ao seu lar, ainda desempenham a função que lhes foi naturalmente atribuída, o papel de servir ao marido, cuidar dos filhos e da casa. A fragilidade não é algo que elas conhecem, pois desde crianças precisaram aprender que sua vida era diferente e mais dura, e que a sobrevivência dos seus dependeria da força dos seus braços e da sua capacidade de resistir. Do ponto de vista das classes sociais, pode-se distinguir, basicamente, dois sentidos da história: o das classes dominantes e o das classes subalternas.

Do ângulo das categorias de sexo, as mulheres, ainda que façam história, têm constituído sua face oculta. A história oficial pouco ou nada registra da ação feminina no devir histórico. A sociedade não está dividida entre homens dominadores de um lado e mulheres subordinadas de outro. Há também homens que dominam outros homens, mulheres que dominam outras mulheres, e mulheres que dominam homens (SAFFIOTI, 1987). $O$ patriarcado, sistema de relações sociais que garante a subordinação da mulher ao homem, não constitui o único princípio estruturador da sociedade brasileira. A divisão da população em classes sociais, profundamente desiguais, representa outra fonte de dominação, considerada absolutamente legítima pelos poderosos, e o mesmo acontece com as diversidades étnicas. Todavia, a história da humanidade nem sempre foi assim. Na Antiguidade as mulheres eram consideradas seres superiores, pois eram "capazes de engendrar uma nova vida, de produzir todos os nutrientes necessários ao desenvolvimento dos fetos e, ainda, de fabricar internamente leite para alimentar seus bebês, [portanto] eram consideradas seres poderosos, mágicos, quase divinos" (SAFFIOTI, 2004, p. 33). Deixaram 
esse posto quando o homem tomou conhecimento de que sua participação era imprescindivel para a geração de uma nova vida. A partir daí, o homem sentiu-se superior e passou a dominar a mulher nas múltiplas áreas da vida cotidiana.

Nas comunidades primitivas, as tarefas eram divididas entre caça e coleta. Contudo, os homens não eram destinados à caça por serem fortes, nem as mulheres ficavam responsáveis pela coleta por serem fracas. Como as mulheres precisavam carregar seus filhos junto de si, pois tinham que amamentar os bebês, e como o choro da criança poderia afugentar a presa, ficavam responsáveis por coletar frutos, raízes e folhas. Porém, a caça era incerta, e nem todo dia era possivel abater um grande animal, mas a coleta era algo certo. Dessa forma, as mulheres eram responsáveis por grande parte da alimentação do grupo (SAFFIOTI, 2004). A elite dominante tem interesse na existência de categorias sociais discriminatórias: mulheres, negros, homossexuais. Quanto mais discriminada uma categoria social, mais facilmente ela se sujeitará a trabalhar em condições precárias e por baixos salários, aumentando, assim, os lucros do capital. "O pré-conceito nasce do jogo de interesses presente na vida social, da defesa de privilégios, da correlação de forças político-sociais" (SAFFIOTI, 1987, p. 29). A manutenção dos preconceitos interessa àqueles que pagam salários irrisórios a negros e mulheres, submetendo-os a condições subumanas de trabalho e negando-lhes o direito à carteira de trabalho assinada. Não é por acaso que tais preconceitos são nutridos e alimentados cotidianamente pelos meios de comunicação de massa, cujo controle está nas mãos dos poderosos.

A ideologia machista, que considera o homem um ser superior à mulher, não entra apenas na cabeça dos homens, mas está também na cabeça de algumas mulheres que acreditam nessas ideias e transmitem-nas aos filhos. Simone de Beauvoir (1967) afirma que não existe nenhum destino biológico, psíquico ou econômico que seja capaz de definir a forma que a fêmea humana assume na sociedade. Desde o momento da gestação e da descoberta do sexo da criança, a sociedade já impõe qual será o seu destino e, dessa forma, impõe quais padrões deverão ser seguidos. As roupas, os brinquedos, a maneira de se comportar, como falar: tudo isso é construído socialmente. A passividade que caracteriza essencialmente a mulher como feminina é um traço que se desenvolve nela desde os primeiros anos. É um destino que lhe é imposto pela familia e pela sociedade.

[...] aceitando a passividade, ela aceita também suportar, sem resistência, um destino que the será imposto de fora, e essa fatalidade amedronta-a. Seja ambicioso, 
parvo ou tímido, é para um futuro aberto que o menino se atira; será marinheiro ou engenheiro, ficará no campo ou irá para a cidade, verá o mundo, tornar-se-á rico; sente-se livre em face de um futuro em que possibilidades imprevistas o aguardam. A menina será esposa, mãe, avó; tratará da casa, exatamente como fez sua mãe, cuidará dos filhos como foi cuidada: tem 12 anos e sua história já está escrita no céu [...]. (BEAUVOIR, 1967, p. 40).

Diferentemente do menino, que cresce ante um leque de possibilidades e caminhos a desvendar, a menina tem seu destino traçado sem o seu consentimento, pelo simples fato de ser mulher. Desde a infância ela é treinada para, no futuro, exercer um papel que já foi determinado previamente. Ensinam-na a cozinhar, a costurar, a cuidar da casa; ela aprende que, para ser graciosa, deverá reprimir seus movimentos espontâneos; não lhe é permitido ter atitudes que são consideradas de menino; proíbem-na de exercícios violentos e brigas. Diante disso, a menina constata, via ensinamento-doutrinação, que o cuidado das crianças cabe à mãe, e encorajam-na a encantar-se com essas riquezas futuras. Sua "vocação" é imperiosamente ditada.

Segundo Saffioti (2004), o conceito de gênero não se resume a uma categoria de análise, mas a uma categoria histórica: a construção social do masculino e do feminino. $E$, como tal, o gênero pode ser concebido em várias instâncias como aparelho semiótico, tendo símbolos culturais evocadores de representações, conceitos normativos com grade de interpretação de significados, e uma gramática sexual, regulando não apenas as relações homem-mulher, mas também relações homem-homem e relações mulher-mulher. Portanto, pode-se perceber que o papel representado pela mulher na sociedade é construído historicamente desde a infância; existem papéis com prestígio social destinados a homens brancos e ricos e a mulheres brancas e ricas. Já o lugar ocupado pela mulher negra e que vive em situação de pobreza é sempre o mesmo: à margem de tudo, sem os mesmos direitos e possibilidades de acesso. Sua vivência resume-se em servir ao outro e enfrentar as diversas formas de preconceitos e violências.

\section{A atribuição cultural de papéis sociais}

Durante a infância a menina é constantemente reprimida e mutilada. Entretanto, ela se percebe como um indivíduo autônomo em suas relações com os pais e amigos, chegando a sonhar e idealizar sua futura passividade. Uma vez na puberdade, o futuro não apenas se aproxima como também se instala em seu corpo e torna a realidade mais concreta. Enquanto o 
adolescente se encaminha ativamente para a idade adulta, a jovem aguarda o início desse período novo, imprevisível, cuja trama já se acha traçada e para a qual o tempo a arrasta. É por volta dos treze anos que os meninos fazem um verdadeiro aprendizado da violência, desenvolvendo sua agressividade, sua vontade de poder e seu gosto pelo desafio. É exatamente nesse mesmo momento que a menina renuncia aos jogos brutais, pois brigas e violência são coisas de menino, e a ela não é permitido ter tal comportamento.

Para Beauvoir (1967), o universo tem um aspecto inteiramente diferente para $\circ$ adolescente a quem se permite testemunhar imperiosamente a si mesmo e para a adolescente cujos sentimentos se acham privados de eficiência imediata. Enquanto o menino pode colocar o mundo em discussão incessantemente, questionando situações e rebelando-se contra elas, a menina não faz nada senão suportar todas as angústias e indagações que surgem. $\bigcirc$ mundo se define sem a mulher e tem um aspecto imutável. A impotência física traduz-se numa timidez mais geral, voltada à docilidade e à resignação, cuja única alternativa é aceitar, na sociedade, um lugar já preparado. As ações e condutas da jovem exprimem sua situação e se modificam ao longo do tempo. Diferentemente do que ocorreu com sua mãe e avó, hoje lhe é permitido tomar o destino nas mãos em vez de entregá-lo ao homem. Absorvida nos estudos, nos esportes e em um aprendizado profissional, liberta-se da obsessão do homem e preocupa-se muito menos com seus conflitos sentimentais e sexuais.

Entretanto, a jovem mulher tem muito mais dificuldade do que o rapaz em se realizar como indivíduo autônomo, pois nem a família nem os costumes favorecem seu esforço. Durante toda a infância, ela foi preparada para desempenhar um papel, sua espontaneidade foi amputada, e seu comportamento foi moldado de acordo com os padrões esperados pela sociedade. Mesmo que escolha a independência e o sucesso profissional, intimamente reserva um lugar em sua vida para o homem e para o amor. $\bigcirc$ medo é o companheiro intimo da jovem, que tem medo de falhar em seu destino de mulher ao dedicar-se ao trabalho ou ao abdicar dos ideais que lhe foram transmitidos de geração em geração, que é o tão esperado papel de mãe e esposa.

Segundo Beauvoir (1967), o destino que a sociedade propõe tradicionalmente à mulher é o casamento. Em sua maioria, ainda hoje, as mulheres são casadas, ou já foram, ou se preparam para sê-lo, ou sofrem por não ser. Portanto, o "casamento sempre se apresentou de maneira radicalmente diferente para o homem e para a mulher" (BEAUVOIR, 1967, p. 166). Todavia, a evolução econômica da condição feminina está modificando 
profundamente a instituição do casamento. Este vem tornando-se uma união livremente consentida por duas individualidades autônomas. A mulher não se acha mais confinada à sua função reprodutora, pois esta perdeu em grande parte seu caráter de servidão natural e hoje apresenta-se como um encargo voluntariamente assumido.

A liberdade de escolha da jovem sempre foi muito restrita, e o casamento, durante muito tempo, foi visto como uma forma de subsistência financeira e única justificativa social de sua existência. A ela foi imposta a tríplice função de dar filhos à comunidade, satisfazer as necessidades sexuais de um homem e tomar conta do lar. Assim, para ambos os cônjuges, o casamento é concomitantemente um encargo e um benefício, mas não há simetria nas situações, para as jovens, pois o casamento é o único meio de se integrar na coletividade. Segundo Beauvoir (1967), a jovem é casada, ou seja, dada em casamento pelos pais. Já os rapazes resolvem se casar. Buscam no casamento uma expansão, uma confirmação de sua existência; é um encargo que assumem livremente, ao contrário da mulher, que aceita passivamente tal imposição. "Socialmente, o homem é um indivíduo autônomo e completo; ele é encarado antes de tudo como produtor e sua existência justifica-se pelo trabalho que fornece à coletividade" (BEAUVOIR, 1967, p. 166). $\bigcirc$ cuidado com a casa, com o marido e as preocupações com os filhos (se estão indo bem na escola, se estão saudáveis etc.) são situações cotidianas que acompanham a rotina da mulher, e não do homem, pois a ele cabe apenas prover o sustento. Essas tarefas do dia a dia são obrigações da esposa, pois ela se casou para isso.

Dessa forma, a vida das mulheres é uma eterna gangorra, tentando equilibrar, de um lado, as aspirações profissionais e os anseios de uma vida independente e, de outro, o árduo papel de atender às expectativas de ser uma boa mãe e esposa. E no meio disso tudo, o sentimento de culpa ronda muitas mulheres, por se sentirem incapazes de realizar tantas atividades ao mesmo tempo, ou pelo medo de estarem perdendo momentos preciosos ao lado dos filhos enquanto buscam a tão sonhada realização profissional. Rigorosamente, os seres humanos nascem machos ou fêmeas. É através da educação que se tornam homens e mulheres. A identidade de gênero é, portanto, socialmente construída.

A construção social da supremacia masculina exige a construção social da subordinação feminina. Mulher dócil é a contrapartida de homem macho. Mulher frágil é a contrapartida de macho forte. Mulher emotiva é a 
outra metade do homem racional. Mulher inferior é a outra face da moeda do macho superior. Geralmente a mulher é associada a adjetivos considerados negativos, tais como: emoção, fragilidade, resignação, incapacidade de usar a razão, insegurança e histeria. Essas características são apresentadas como inerentes à mulher, isto é, como algo que a mulher traz desde o nascimento. E são esses estereótipos que moldam e afirmam a inferioridade da mulher em relação ao homem. Para Saffioti (2004), as mulheres são "amputadas", sobretudo no desenvolvimento e uso da razão e no exercício do poder. Elas são socializadas para desenvolver comportamentos dóceis e apaziguadores. Já os homens, ao contrário, são estimulados a desenvolver condutas agressivas e perigosas, que revelem sua força e coragem. $\bigcirc$ poder político é um exemplo disso. Nas sociedades contemporâneas, a participação política da mulher é considerada ínfima. $\bigcirc$ mesmo se pode afirmar sobre a presença feminina nos partidos políticos. Quando a mulher participa, em geral, encarrega-se de funções menores, sendo rara sua presença em cargos de comando. A subordinação da mulher ao homem, contudo, não existe somente no terreno político. Ela é marcante no campo econômico, pois a presença da mulher é relativamente maior que a masculina no mercado informal de trabalho.

Dessa forma, quase todo o setor do emprego doméstico está ocupado por mulheres, cuja presença é também maciça no trabalho em domicilio. Ainda que a mulher trabalhe fora de casa em troca de um salário, cabe- Ihe a obrigação de realizar todas as tarefas domésticas. A noção de divisão sexual do trabalho foi utilizada, primeiramente, pelos etnólogos para designar uma repartição complementar das tarefas entre os homens e as mulheres nas sociedades que eles estudavam. Contudo, foram as antropólogas feministas que primeiro trouxeram um conteúdo novo demonstrando que tal noção traduzia não uma complementaridade de tarefas, mas sim uma relação de poder dos homens sobre as mulheres. Segundo Danièle Kergoat (2009, p. 67), a "divisão sexual do trabalho é a forma de divisão do trabalho social decorrente das relações sociais de sexo; essa forma é historicamente adaptada a cada sociedade". Ao ingressar no mercado de trabalho, a mulher enfrenta não apenas o preconceito, mas também diversos obstáculos, como os princípios da separação e de hierarquia - que determinam a existência de trabalhos destinados a homens e a mulheres -, além da ideologia que diz que o trabalho realizado pelo homem tem mais valor que o trabalho realizado pela mulher. 
Esses dois princípios permeiam as relações sociais no ambiente de trabalho e são eles que embasam o discurso conservador e machista da sociedade, que destina às mulheres os trabalhos com remunerações mais baixas e com menor prestígio, além de afirmar sua fragilidade e incapacidade de exercer determinadas funções sociais. Aos homens são destinados os holofotes, o papel de macho forte e provedor; a mulher, entretanto, vive à sua sombra, exercendo seu papel de submissa, mãe, esposa e trabalhadora.

Segundo Hirata e Kergoat (1994), a classe operária foi durante muito tempo vista como uma classe homogênea, ou seja, sem distinções entre os sexos, de modo que o termo "operário" era utilizado para determinar tanto homens quanto mulheres. Todavia, para as autoras, o pertencimento de classe para a mulher é construído a partir de um referencial exclusivo, o homem (seja ele o marido ou o pai), sem levar em consideração as atividades próprias da mulher. Dessa forma, as classes sociais são abordadas como se o fator gênero não implicasse nenhuma heterogeneidade em sua composição, seus comportamentos e práticas. As relações de classe e de gênero são relações estruturantes e fundamentais da sociedade e estão presentes em todas as esferas da vida cotidiana. Para Hirata e Kergoat (1994, p. 96), "não é só em casa que se é oprimida, nem só na fábrica que se é explorado(a)". Há, dessa forma, um duplo movimento entre classe social e gênero que permeia todas as relações sociais.

\section{A desigualdade de gênero e sua interface com etnia e classe social}

A familia, independentemente dos formatos ou modelos que assume, é mediadora das relações entre os sujeitos e a coletividade. Ela se caracteriza como um espaço contraditório, cuja dinâmica cotidiana de convivência é marcada por conflitos e situações de desigualdades. Segundo a Política Nacional de Assistência Social (PNAS), podemos dizer que estamos diante de uma família "quando encontramos um conjunto de pessoas que se acham unidas por laços consanguíneos, afetivos e, ou, de solidariedade" (BRASIL, 2005, p. 41). A configuração do modelo familiar sofreu algumas alterações no período entre os anos de 1995 e 2015. Em 1995, o tipo tradicional de família, composta pelo casal e filhos, respondia a $58 \%$ das famílias. No ano de 2015 esse número era de 42\% (FONTOURA et al., 2017). Houve no período um aumento significativo no número de casas com uma só pessoa e casais sem filhos. 
Essa alteração se deve a alguns fatores: primeiro, a difusão da pílula anticoncepcional na década de 1960, que possibilitou a separação entre sexualidade e reprodução e interferiu decisivamente na sexualidade feminina. Para Sarti (2002, p. 22), essa conquista "criou condições materiais para que a mulher deixasse de ter sua vida e sua sexualidade atadas à maternidade como um 'destino", e recriou o mundo subjetivo feminino, ampliando as possibilidades de atuação da mulher na vida em sociedade. A maternidade deixou de ser vista como algo natural e imposto pelos padrões da sociedade e tornou-se uma questão de escolha.

Em segundo lugar, podemos citar a possibilidade de decisão da mulher de contrair ou não matrimônio. Retomando o que foi dito por Saffioti (1987), uma das diferenças entre os gêneros em relação ao casamento é que o homem se casa por opção, enquanto a mulher é dada em casamento a alguém. Contudo, com os avanços tecnológicos, as descobertas da medicina e a segunda onda do movimento feminista em todo o mundo, assuntos antes vistos como tabus da sociedade começam a ser discutidos e questionados, tais como: a descoberta da sexualidade, o direito de decidir sobre o próprio corpo, além da escolha de se casar ou não.

Nessa esteira temos, como terceiro fator, o rompimento com o modelo idealizado e tradicional de família (com casal e filhos) e o surgimento de novas configurações, apenas com um casal ou com familia homoafetiva, por exemplo. Esses são alguns dos fatores que explicam essa nova composição familiar apresentada pelos dados citados. $\bigcirc$ respeito à dignidade humana é defendido pela Constituição Federal, logo os relacionamentos afetivos são alvo de proteção, independente da sua formação: com homens e mulheres, ou só mulheres, ou só homens.

Para Dias (2005, p. 47), "mesmo que se conceitue família como uma relação interpessoal entre um homem e uma mulher tendo por base o afeto, é necessário reconhecer que há relacionamentos que, mesmo sem a diversidade de sexos, são cunhados também por um elo de afetividade". modelo de família herdado dos anos 1950, no qual o pai sai para trabalhar e a mãe fica em casa dedicando-se ao lar e aos filhos, está deixando de ser hegemônico. Segundo Jablonski (2010), atualmente, nos centros urbanos, encontra-se em maior ou menor número famílias nas quais pais e mães trabalham fora, outras compostas por pais ou mães em segunda união matrimonial, ou por mães solteiras que assumiram a maternidade, ou por casais que moram juntos, ou por casais homossexuais. São formas 
alternativas que se contrapõem ao modelo tradicional e vão redefinindo, na prática, o conceito de família.

Segundo Sarti (2002), no universo simbólico das pessoas que vivem em situação de pobreza, existe uma divisão complementar de autoridades entre o homem e a mulher na família, que corresponde à diferenciação que fazem entre casa e família. A casa é identificada com a mulher, e a familia com o homem. Casa e familia, como mulher e homem, constituem um par complementar, mas hierárquico. Outra categoria significativa para esta análise é a de domicilios chefiados por mulheres, que em 1995 eram $23 \%$; já em 2015 , esse número aumenta para $40 \%$, sendo que $34 \%$ desses lares chefiados por mulheres contam com a presença do cônjuge. Esse é um fenômeno majoritariamente urbano: nas cidades houve um aumento de aproximadamente $18 \%$ no número de casas chefiadas por mulheres entre 1995 e 2015. No campo esse aumento é, em média, de 10\% (FONTOURA et al., 2017). Isso demonstra uma maior participação feminina no mercado de trabalho e uma nova configuração na situação econômica da família, pois no passado o salário da mulher servia apenas como um complemento ao do marido, e nunca como principal fonte de renda. Contudo, nos casos em que a mulher assume a responsabilidade econômica do lar, ocorrem modificações importantes no jogo de relações de autoridade, de modo que ela pode de fato assumir o papel de "chefe de família" e se definir como tal.

Como já abordado por Davis (2013), mulheres em situação de pobreza se veem obrigadas a somar ao papel de mãe e especialista em domesticidade a função de trabalhadora para além do ambiente doméstico, em prol da sua sobrevivência e dos filhos. Ingressando cada vez mais cedo no mercado de trabalho e com pouca qualificação, a elas são destinados os trabalhos mais precários e mal remunerados. Sarti (2002) afirma que a sobrevivência dos grupos domésticos das mulheres "chefes de familia" é possibilitada pela mobilização cotidiana de uma rede familiar que ultrapassa os limites da casa. Tal como acontece o deslocamento dos papéis masculinos, os papéis femininos, na impossibilidade de serem exercidos pela mãe-esposa-dona de casa, são igualmente transferidos para outras mulheres, de fora ou de dentro da unidade doméstica. Já no campo o avanço é mais lento, pois ali o machismo e o patriarcado ainda têm forte presença e influência na vida e nas decisões das mulheres - sem falar que nesses lugares a mulher trabalha junto com o marido na lavoura, com pouca ou nenhuma diferença de intensidade de trabalho. 
Outra categoria que deixa clara a desigualdade existente entre gênero, classe social e etnia é a educação. $\bigcirc$ fator escolaridade influencia diretamente outra categoria a ser aqui analisada: o mercado de trabalho. Abordamos na segunda seção que existem funções com maior ou menor prestígio social destinadas a cada gênero, e isso fica claro na participação em cursos de ensino superior tidos como função de mulher ou função de homem. Segundo Marcondes et al. (2013), a participação feminina é maior em cursos considerados de menor prestígio social, como a área da educação, na proporção de $70 \%$ de mulheres para apenas $30 \%$ de homens, o que se deve à docilidade e à função maternal naturalmente atribuída ao gênero feminino. Já em áreas com maior prestígio, como engenharia, produção e construção, a presença masculina é superior à feminina, sendo $28 \%$ mulheres e $72 \%$ homens, o que reforça o preconceito e o estereótipo da incapacidade da mulher para determinadas funções, enquanto exalta a força e a masculinidade do homem.

Como já abordado por Beauvoir (1967), não existe nenhum fator biológico que determine a inferioridade da mulher diante do homem. Esses papéis sociais são construídos pela sociedade ao longo do tempo, e cabe a cada um de nós desmistificar esses pré-conceitos. $\bigcirc$ Gráfico 1 apresenta a taxa de escolarização no nível do ensino médio, nos anos de 1995 e 2009, de acordo com as categorias gênero e etnia.

Gráfico 1: Taxa de escolarização no nível do ensino médio em 1995 e 2009

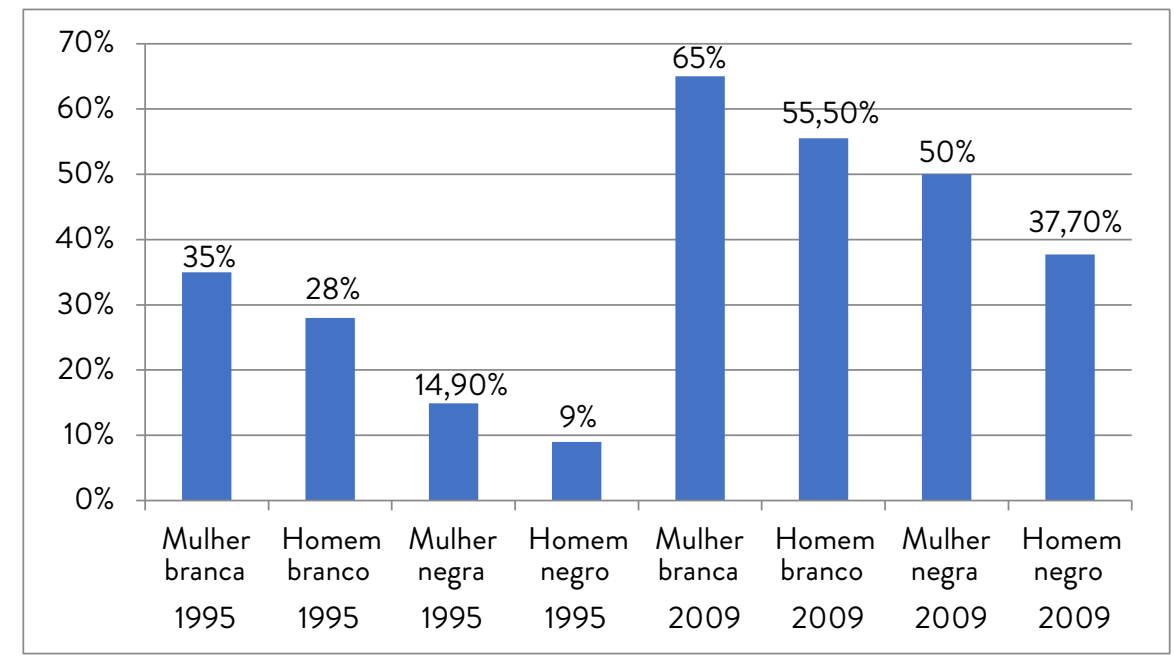

Fonte: Marcondes et al. (2013). 
Para entender o quanto essa diferença de acesso à educação é significativa, faz-se necessário voltar o olhar para o passado e compreender sobre quais raízes nossa sociedade foi constituída. Segundo Silva (2014, p. 46), enfrentamos "um processo colonizador devastador de homens e recursos naturais, que contribuiu, culturalmente, para o Brasil que somos hoje: a mestiçagem de brancos, índios e negros". Esse processo resultou na discriminação e no preconceito que a população negra sofre diariamente neste país, não apenas pela cor de sua pele, mas também uma discriminação social. Para a autora, essa inferioridade presente na sociedade está relacionada à sua forma de incorporação brusca e sem preparo algum (SILVA, 2014).

Esse argumento retoma o que foi abordado por Davis (2013), conforme exposto na primeira seção deste artigo: diferentemente dos índios, que tiveram nas missões jesuíticas um início de educação, os negros, por sua vez, foram arrancados de suas terras e tratados como párias sociais. A sua condição de escravo impediu que o negro pudesse contribuir, com a sua cultura, na formação da sociedade. Para Silva (2014, p. 50), o negro foi "esterilizado e amputado de suas qualidades naturais, restando-lhe apenas os defeitos, como elementos corruptores, resultando na formação de uma cultura 'inferior' à do branco". pré-conceito em torno dessa dita inferioridade se reflete diretamente no acesso à educação. $\bigcirc$ Gráfico 1 mostra que a população negra se encontra sempre abaixo da população branca não por opção, mas por falta de oportunidades, visto que para ela a prioridade não é a educação, mas sim a sobrevivência.

Com um ingresso cada vez mais precoce no mercado de trabalho e exaustivas jornadas laborais, torna-se cada vez mais difícil conciliar estudo e trabalho. A questão aqui é que os negros nunca estiveram em condições de igualdade com os brancos para disputar as mesmas posições e o mesmo prestígio. Nesse contexto, a categoria etnia permeia todas as relações sociais e, junto com a categoria gênero, é capaz de delimitar a ordem hierárquica imposta pela sociedade. É possivel perceber nesse recorte temporal um aumento nos índices de escolarização de ambos os gêneros, mas, apesar desse avanço, os índices da população negra não se igualam aos indices da população branca. Em relação ao acesso ao ensino superior, essa diferença é ainda maior, como podemos observar no Gráfico 2. 
Gráfico 2: Taxa de escolarização no nível do ensino superior em 1995 e 2009

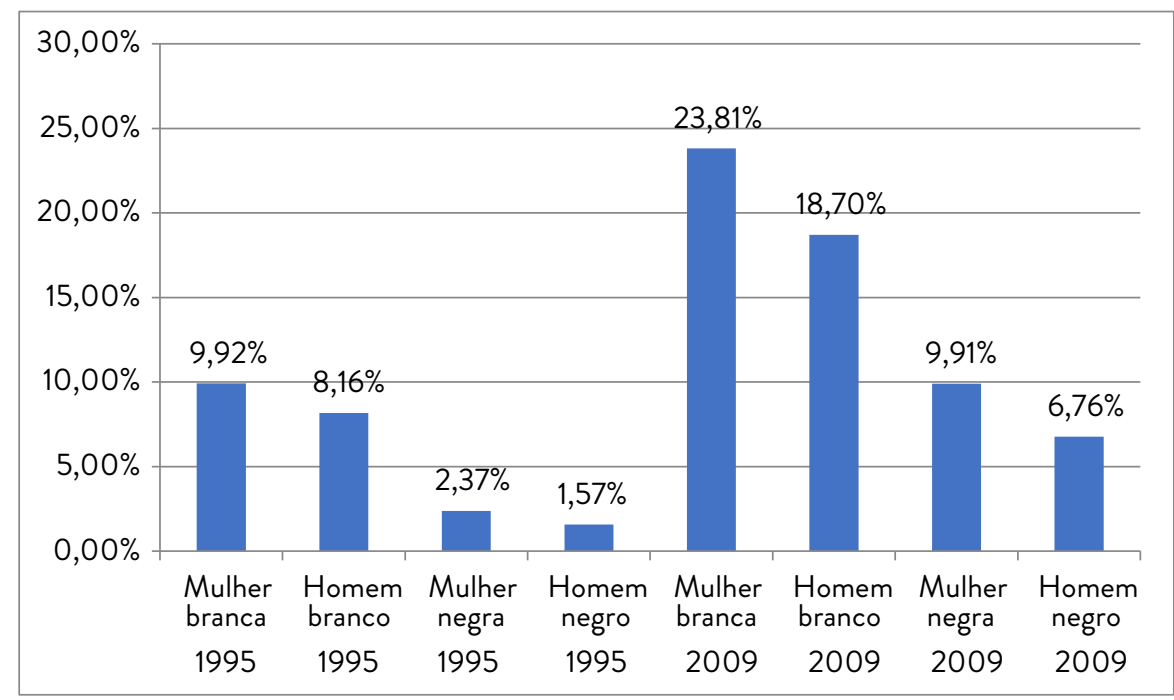

Fonte: Marcondes et al. (2013).

Gráfico 2 mostra um aumento significativo de escolarização em relação à população branca e evidencia o abismo existente no acesso da população negra à educação. Mesmo com um salto de dez anos, essa diferença não diminui; pelo contrário, aumenta. Alguns dos fatores determinantes para isso são a dificuldade de acesso ao ensino superior e a ideia errônea de que todos possuem as mesmas oportunidades, o que não passa de uma ilusão e de um discurso conservador que exalta o esforço pessoal e a meritocracia. Analisando apenas o percentual referente à população negra, percebe-se que, mesmo que pouco, houve um avanço no acesso ao ensino superior. Isso se deve em grande parte à implementação de políticas de cotas raciais nas universidades, que significou uma oportunidade de mudança de perspectiva de vida para inúmeros jovens.

No Brasil, as lutas por cotas raciais eclodem na década de 1990, impulsionadas por organizações não governamentais, pela sociedade civil e, principalmente, pelas reivindicações do movimento negro por ações mais igualitárias e políticas de não segregação e não discriminação. Classificadas dentro das ações afirmativas, as políticas de cotas raciais têm a intenção de provocar o resgate de uma divida social com um segmento da sociedade que, historicamente, vem sendo discriminado. As ações afirmativas são medidas temporárias e especiais, tomadas ou determinadas pelo Estado, de forma compulsória ou espontânea, com o propósito específico 
de eliminar as desigualdades que foram acumuladas no decorrer da história da sociedade. Essas medidas têm como principais beneficiários os membros dos grupos que enfrentam preconceito (PEREIRA; RODRIGUES; GUILHERME, 2010).

Assim, a política de ações afirmativas tem o viés de sanar dívidas sociais, evidenciando-se que não precisam ser vistas como um "favor", mas sim como um direito adquirido. A discriminação e desvalorização presentes em nossa sociedade fizeram com que os negros fossem expulsos e empurrados continuamente para as margens da sociedade, sem condições concretas de construir a perspectiva da conquista de melhores postos de trabalho e remuneração (SILVA, 2014). À baixa remuneração soma-se o baixo índice de escolaridade, ou seja, todo esse contexto contribuiu para que, ainda hoje, pouquíssimos negros e pardos consigam ingressar na escola pública e continuar os estudos em instituições de nível superior.

Outra categoria de análise é o trabalho, que no capitalismo assume algumas particularidades, como a venda e exploração da força de trabalho e o enriquecimento do capital. Nesse contexto, a prioridade não é a divisão da riqueza, mas sim a acumulação. $\bigcirc$ capitalismo é um sistema voraz que se apropria não apenas da matéria-prima disponível na natureza, mas também da vida do trabalhador (MARX, 1984). Com a reestruturação produtiva e a flexibilização dos serviços, os espaços de trabalho tornaram-se mais precários, e a disputa por vagas mais intensa, visto que o número de pessoas à procura de um emprego aumentou consideravelmente nos últimos anos. Esse fato é benéfico para o capital, pois possibilita contratar uma mão de obra mais barata e que se sujeita a qualquer condição imposta pelo empregador (ANTUNES, 2018).

Nesse contexto, o Quadro 1 apresenta a taxa de desemprego nos anos de 1995 e 2009, entre as categorias gênero e etnia.

Quadro 1: Taxa de desemprego em 1995 e 2009

\begin{tabular}{|l|c|c|c|c|c|}
\hline $\begin{array}{c}\text { Categoria com 1 a 4 } \\
\text { anos de escolaridade }\end{array}$ & $\mathbf{1 9 9 5}$ & $\mathbf{2 0 0 9}$ & $\begin{array}{c}\text { Categoria com 12 } \\
\text { anos ou mais de } \\
\text { escolaridade }\end{array}$ & $\mathbf{1 9 9 5}$ & $\mathbf{2 0 0 9}$ \\
\hline Mulher branca & $4,3 \%$ & $5,3 \%$ & Mulher branca & $4,0 \%$ & $5,9 \%$ \\
\hline Mulher negra & $5,8 \%$ & $8,0 \%$ & Mulher negra & $4,1 \%$ & $7,9 \%$ \\
\hline Homem branco & $3,8 \%$ & $2,9 \%$ & Homem branco & $2,5 \%$ & $4,4 \%$ \\
\hline Homem negro & $4,6 \%$ & $4,4 \%$ & Homem negro & $3,7 \%$ & $5,5 \%$ \\
\hline
\end{tabular}

Fonte: Marcondes et al. (2013). 
A taxa de desemprego feminina é maior que a masculina entre brancos e negros, o que se deve fatores como a disputa crescente entre homens e mulheres por postos de trabalho no setor de serviços. Além disso, com a reestruturação produtiva e a terceirização dos serviços, muitas funções antes realizadas apenas por mulheres passaram a ser desenvolvidas também pelos homens, aumentando, assim, a concorrência nesse ramo de atividade. O Gráfico 3 apresenta a taxa de emprego com carteira assinada.

Gráfico 3: Taxa de emprego com carteira assinada no ano de 2009

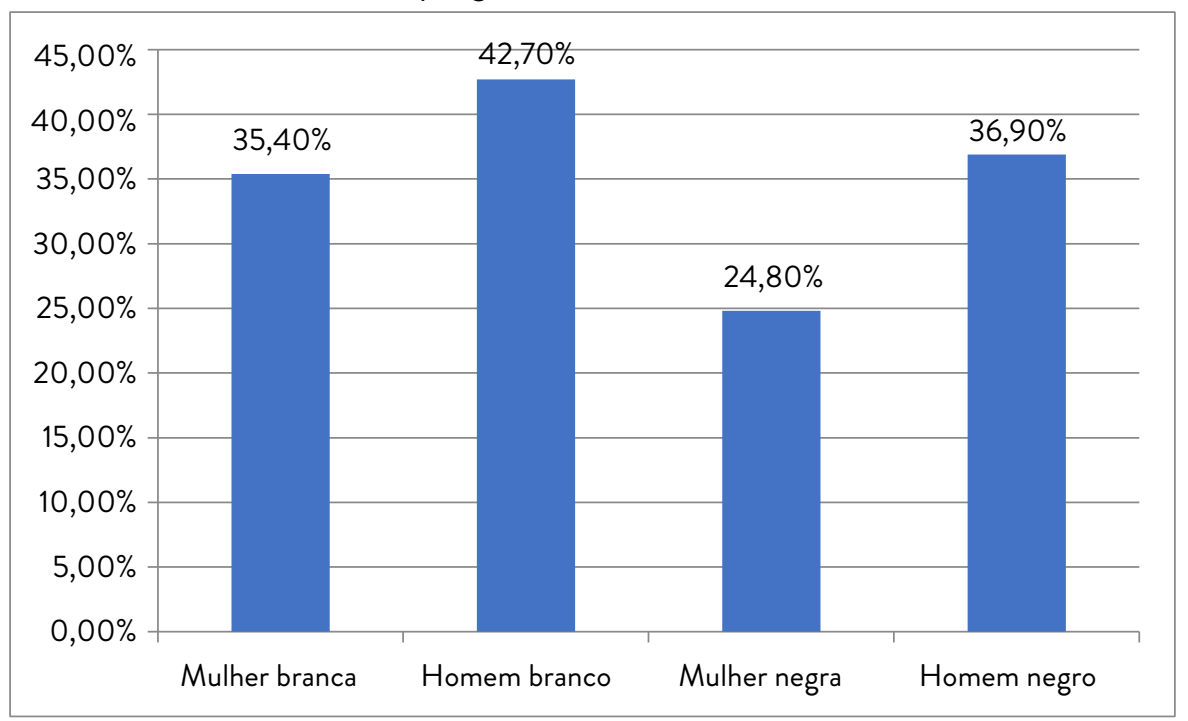

Fonte: Marcondes et al. (2013).

Pode-se perceber que o homem e a mulher branca estão sempre à frente da mulher e do homem negro também no mercado formal de trabalho, ocupando as melhores posições. Isso demonstra que o setor de serviços e o mercado informal são destinados a uma parcela muito específica da população: mulheres, negros e pobres. Saffioti (1997) diz que há uma "ordem das bicadas", organizada por um sistema hierárquico que garantirá sempre o maior poder ao galo. Em um galinheiro com dez galinhas, a última na hierarquia é a que mais sofre, pois é bicada não apenas pelo galo, mas por todas as outras galinhas, não podendo bicar nenhuma. No contexto deste estudo, a metáfora usada por Saffioti (1997) representa a mulher negra que vive em situação de pobreza, sofrendo opressão e discriminação em todas as categorias, como observado nos dados apresentados. $\bigcirc$ Gráfico 4 apresenta um comparativo da taxa de desemprego nos anos de 1995 e 2009. 
Gráfico 4: Taxa de desemprego em 1995 e 2009

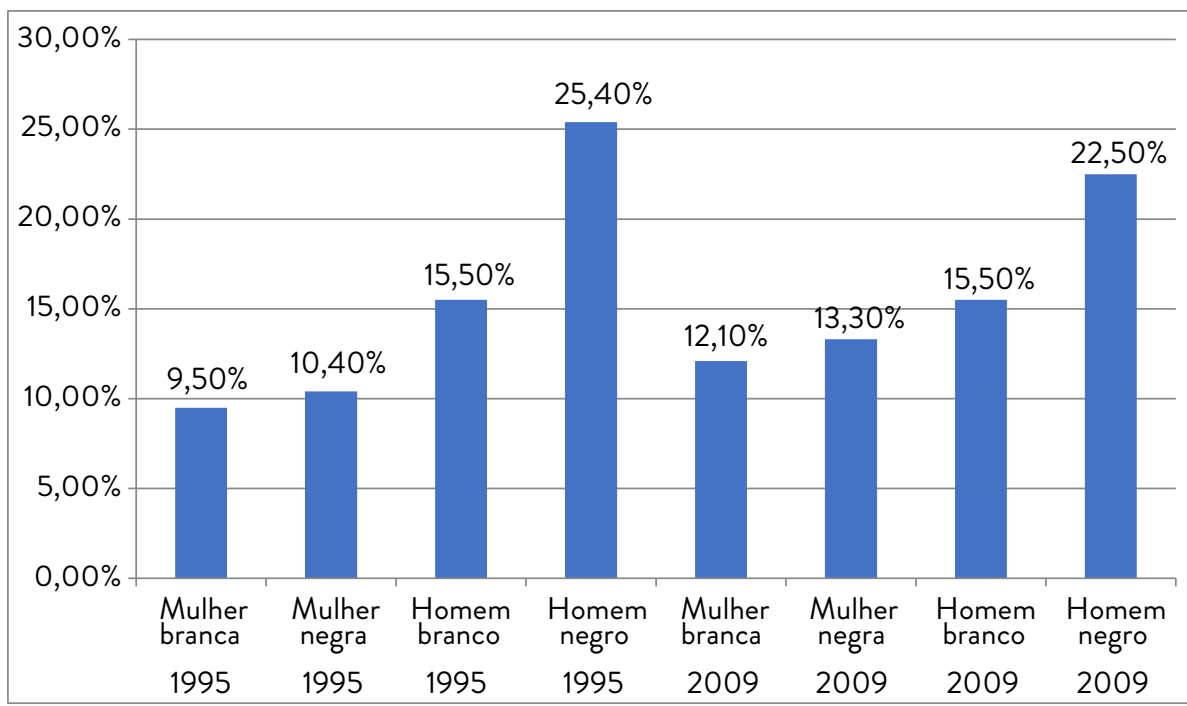

Fonte: Marcondes et al. (2013).

Segundo Lima e Oliveira (2017), existem duas variáveis que interferem na feminização da pobreza: o mercado de trabalho e a questão de gênero. Ao analisar a questão de gênero, observa-se a construção histórica, na qual as mulheres foram inferiorizadas no processo de acesso ao mercado de trabalho. Há falta de apoio à mulher por parte de serviços públicos e apoio ao mercado de trabalho, tendo em vista que as condições e oportunidades da mulher para se profissionalizar são inferiores às dos homens em virtude de sua dupla jornada de trabalho.

A mulher enfrenta um duplo desafio pela posição inferior que ocupa no mercado de trabalho e pelo papel que tem na atenção à família, sem que haja garantia de serviços públicos para atender a crianças e idosos, ou seja, serviços de cuidados. De acordo com Castro (2001, p. 91 apud LIMA; OLIVEIRA, 2017, p. 3), "analisar a feminização da pobreza é abordar a complexidade do sistema: 'O reconhecimento da maior vulnerabilidade social das mulheres é também o reconhecimento de que sistemas de subordinações se cruzam, como os de classe, de raça e de gênero [...]"”. A pobreza é maior nas famílias em que a mulher não trabalha de forma remunerada fora de casa, e isso afeta também as condições de vida das crianças. A feminização da pobreza gera impactos na sociedade, de modo que é crescente o trabalho feminino e, em muitos casos, este se configura como única fonte de renda, além de apresentar médias salariais inferiores 
às masculinas. As mulheres se voltam para o trabalho fora de casa não só porque ele possibilita atingir um melhor padrão de vida para a família, mas também pelo fato de o sucesso profissional ser encarado como uma forma de realização pessoal e social.

Segundo levantamento do Instituto de Pesquisa Econômica Aplicada (Ipea), no ano de 1995, 94\% das mulheres eram responsáveis pelo trabalho doméstico, e esse número diminuiu para $91 \%$ no ano de 2015 (FONTOURA et al., 2017). Em relação aos homens, em 1995, 46\% afirmaram realizar atividades domésticas, e esse número cresceu para 53\% no ano de 2015. Assim, pode-se perceber que, mesmo com o aumento da participação masculina nesse tipo de atividade, continua sendo em proporção inferior à da mulher. Esse é um padrão predominante na sociedade brasileira e acaba reforçando estereótipos de que as funções de cuidado com a casa são atribuição feminina. Para Jablonski (2010), o ingresso das mulheres no mercado de trabalho não implicou uma divisão mais igualitária dos trabalhos domésticos. Há indícios de maior participação masculina no que diz respeito ao cuidado dos filhos, mas não nas tarefas domésticas. Outro dado levantado pelo Ipea é que, quanto maior a renda da mulher, menor é sua dedicação e o tempo destinado a afazeres domésticos: $94 \%$ das mulheres com renda de até 1 salário mínimo afirmam realizar trabalhos domésticos, enquanto para as mulheres com renda entre 5 e 8 salários mínimos esse número cai para 79,5\% (FONTOURA et al., 2017).

Mulheres de classe social mais alta gastam cerca de 13 horas semanais em trabalhos domésticos, o que representa cerca de 11 horas a menos que as mulheres pobres. Além da possibilidade de contratar trabalhadoras domésticas, as famílias com renda mais alta possuem um acesso maior a eletrodomésticos, o que facilita o trabalho e diminuiu o tempo destinado a essas atividades do lar.

Outra categoria de análise é a violência. Como se sabe, uma das principais faces da desigualdade racial no Brasil é a forte concentração de homicídios na população negra. Segundo Cerqueira et al. (2018), no ano de 2016 o índice de homicídios da população branca foi de 16\%, enquanto para a população negra esse percentual sobe para $40,2 \%$, o que representa mais que o dobro do número de homicídios dos brancos. No período entre 2006 e 2016, o número de homicídios de brancos diminuiu 6,8\%, enquanto o da população negra cresceu $23,1 \%$. O Índice de Vulnerabilidade Juvenil à Violência de 2015 demonstra que o risco de um jovem negro ser vítima 
de homicídio no Brasil é 27 vezes maior do que o de um jovem branco (FONTOURA et al., 2017).

Esses dados mostram que, em relação à violência, as configurações das categorias raça, etnia e classe social juntas tendem a reduzir a estimativa de vida de uma parcela da população que, involuntariamente e sem perceber, é colocada na linha de fogo da constante violência que assola o país. Contudo, é importante deixar claro que grande parte das mortes da população negra é decorrente de intervenções policiais. Uma análise realizada pelo Anuário Brasileiro de Segurança Pública revelou que de 5.896 boletins de ocorrência de mortes decorrentes de intervenções policiais, entre os anos de 2015 e 2016 - o que representa 78\% do universo de mortes no período -, 76,2\% das vítimas da atuação da polícia eram negras (CERQUEIRA, 2018). Os dados apresentados revelam que há um perfil construído das frequentes vítimas de homicídios no Brasil: homem, jovem e negro. Esse perfil de vítima é muito mais vulnerável que os jovens não negros, sendo também a principal vítima de ações letais da polícia e o perfil predominante da população prisional no Brasil.

Como já abordado por Davis (2013) e Silva (2014), a população negra carrega ainda hoje marcas da discriminação e do preconceito sofrido ainda na escravidão, que se refletem na marginalização dessa parcela da população. Já a violência contra a mulher é histórica e atinge uma proporção significativa da população feminina, independentemente da raça/etnia, idade ou classe social. No ano de 2016 registrou-se um número de 4.645 mulheres assassinadas no país, o que representa uma proporção de 4,5 homicídios para cada 100 mil brasileiros e um aumento de 6,4\% em 10 anos. Segundo dados do lpea, no período de 2006 a 2016, a taxa de homicídios entre mulheres negras teve um aumento de $15,4 \%$, enquanto para as mulheres brancas houve uma queda de $8 \%$ (FONTOURA et al., 2017). A violência contra as mulheres apresenta-se como uma das várias faces da violação dos direitos humanos (BRASIL, 2006), uma vez que atinge a população feminina cotidianamente, pois se manifesta em seus lares, na rua, no transporte público e em diversos espaços públicos e privados. Em sua maioria, são violências praticadas pelos seus companheiros ou familiares, configurando-se como uma violência de gênero.

A Lei Maria da Penha (Lei n 11.340 , de 7 de agosto de 2006) criou mecanismos para prevenir e coibir a violência doméstica e familiar contra a mulher, definindo-a como "qualquer ação ou omissão baseada no gênero que 
The cause morte, lesão, sofrimento físico, sexual ou psicológico e dano moral ou patrimonial" (BRASIL, 2006, art. $5^{\circ}$ ). Além disso, conceitua diferentes formas de violência contra a mulher, sendo elas: física, psicológica, sexual, patrimonial e moral. Segundo Waiselfisz (2018), o Atlas da violência (2018) registrou no Brasil, no período entre 2006 e 2016, 48.701 homicídios de mulheres, e só o estado do Paraná, nesse mesmo período, registrou 3.118 feminicídios. $\bigcirc$ município de Guarapuava ocupa a $373^{a}$ posição no Mapa da violência 2015, ou seja, está entre os municípios brasileiros com maior índice de feminicídios. Isso significa que, entre 2009 e 2013, 28 mulheres foram assassinadas na cidade (GUARAPUAVA, 2016).

Retomando a metáfora de Saffioti (1997, p. 41), existe uma "ordem das bicadas" construída socialmente, muito mais complexa que a existente entre os galináceos, onde não há um único eixo de hierarquização, mas sim "várias gramáticas para reger o comportamento de homens e mulheres, brancos e negros, de ricos e pobres, de crianças, adultos e velhos". As três gramáticas principais são: (1) a gramática sexual ou de gênero, que regula as relações entre homens e mulheres, entre homens e homens, e entre mulheres e mulheres; (2) a gramática de raçaletnia, que define as relações, por exemplo, entre brancos e negros, determinando que estes obedeçam àqueles; e, por fim, (3) a gramática de classe social, cujas leis exigem comportamentos distintos dos pobres e dos ricos, que para se manter no poder precisam dominar e explorar os pobres. Na sociedade capitalista em que vivemos existe também uma ordem estabelecida hierarquicamente: em primeiro lugar estão os "homens brancos, ricos e adultos. Em segundo e terceiro lugares vêm ou homens negros, sem muito poder econômico e adultos, ou mulheres brancas, economicamente remediadas e adultas" (SAFFIOTI, 1997, p. 42). Essas categorias não ocupam lugares fixos, mas trocam de posição de acordo com as circunstâncias. E em quarto lugar vêm as mulheres negras, pobres e adultas.

\section{Considerações finais}

Ao longo deste estudo, compreendemos as condições enfrentadas pela mulher negra no período escravocrata e quais resquícios de preconceito podemos encontrar atualmente. Nesse contexto, o papel social da mulher era delimitado por sua raça, sendo a mulher branca a esposa e mãe, e a mulher negra vista como objeto de satisfação sexual. Quando os senhores de escravos tomaram conhecimento de que, ao engravidar as mulheres 
negras, poderiam aumentar o número de seus escravos sem precisar dispor de recursos financeiros, passaram a vê-las também como um instrumento para o crescimento da força de trabalho.

Com o fim da escravidão estabelecem-se os papéis sociais destinados aos negros que vemos atualmente. A eles foram relegados os trabalhos braçais, exaustivos, mal remunerados e sem prestígio social; e às mulheres negras os serviços domésticos, cuidados com a casa e com os filhos de uma elite ociosa, um trabalho também considerado sem prestígio social e de baixa remuneração.

$O$ preconceito de gênero foi construído, uma vez que na Antiguidade a mulher era considerada um ser divino, capaz de gerar uma vida e com seu corpo possibilitar todos os nutrientes necessários ao desenvolvimento do bebê. Mas no momento em que o homem toma conhecimento de que a sua participação é indispensável para gerar essa nova vida, sente-se superior à mulher e passa a construir processos e formas de dominação e exploração.

Os papéis sociais são culturalmente atribuídos a homens e mulheres desde o momento da gestação, uma vez que a sociedade dita qual o destino bebê: se for menino, vai conhecer o mundo e viver diversas aventuras, pois o mundo do menino é de movimento (bola, carrinhos, armas, ferramentas etc.); se for menina, estará destinada a ser uma boa mãe e esposa, como também à estabilidade e ao ambiente doméstico (bonecas, bebês, panelas, casinhas etc.). Apesar das mudanças culturais que se vislumbram atualmente, ainda há muitos desses resquícios na sociedade presente. Meninos e meninas são preparados de maneira diferente para enfrentar a vida adulta. Os meninos são estimulados a ter ousadia e rebeldia, e sua força e masculinidade precisam ser reforçadas desde muito cedo. As meninas, pelo contrário, têm suas asas amputadas e seu comportamento precisa ser ditado: nada de gestos bruscos e atividades violentas; ela precisa ser dócil, amável, dedicada.

Essa diferença entre os sexos se reflete na futura profissão que cada um irá escolher, pois ao homem são reservadas posições de prestígio e com altos salários, além do papel de provedor e chefe do lar. À mulher é destinado o papel de boa mãe e, como boa esposa, deve não apenas zelar do lar, mas também trabalhar fora para "ajudar" seu marido, afinal essa função lhe foi imposta ao dizer um "sim" no altar.

Os dados estatísticos mostraram a desigualdade de gênero e sua interface com etnia e classe social. Para a consecução de tal objetivo, foram delimitadas algumas categorias de análise, tais como: modelo familiar, domicilios chefiados por mulheres, cursos superiores com maior e menor prestígio social, 
acesso à educação, mercado de trabalho e violência. Em todas as categorias analisadas existe a associação dos fatores classe social, gênero e etnia, e estes determinam quais as oportunidades e o tipo de vida destinados a cada pessoa. Esses dados demonstram que existe uma ordem hierárquica na sociedade e que mulheres negras vivendo em situação de pobreza são as principais vítimas não apenas da violência, mas também de condições desumanas de sobrevivência, visto que a elas são destinados os menores salários e o mercado informal de trabalho.

Conclui-se que o patriarcado ainda exerce forte influência na vida das mulheres. A opressão sofrida diariamente por inúmeras delas é fruto de uma sociedade que se constitui sobre bases machistas e conservadoras, que recrimina e discrimina todas as minorias. A representação social da mulher é construída social e culturalmente, e as relações de classe e de gênero são estruturantes e fundamentais na sociedade, estando presentes em todas as esferas da vida cotidiana.

\section{Referências}

ANTUNES, R. O privilégio da servidão: o novo proletariado de serviços na era digital. São Paulo: Boitempo, 2018.

BEAUVOIR, S. O segundo sexo, II: a experiência vivida. Tradução de Sérgio Milliet. São Paulo: Difusão Europeia do Livro, 1967.

BRASIL. Política Nacional de Assistência Social: PNAS/2004: Norma Operacional Básica NOB/SUAS. Brasilia, DF: Ministério do Desenvolvimento Social e Combate à Fome, 2005.

BRASIL. Lein ${ }^{0} 11.340$, de 7 de agosto de 2006. Lei Maria da Penha. Diário Oficial da União, Brasilia, DF, p. 1, 8 ago. 2006. Disponivel em https://bit.ly/2AYFv3v. Acesso em: 30 jul. 2019.

CERQUEIRA, D. et al. (coord.). Atlas da violência 2018. Rio de Janeiro: Ipea: FBSP, 2018. Disponivel em: https://bit.ly/37Zn36T. Acesso em: 24 jun. 2020.

DAVIS, A. Mulher, raça e classe. Tradução livre. [S. I.]: Plataforma Gueto, 2013.

DIAS, M. B. Família homoafetiva. In: DIAS, M. B. União homossexual: o preconceito e a justiça. 3. ed. Porto Alegre: Livraria do Advogado, 2005. p. 39-63. 
FONTOURA, N.; REZENDE, M. T; MOSTAFA, J.; LOBATO, A. L. Retrato das desigualdades de gênero e raça: 1995 a 2015. Brasilia, DF: Ipea, 2017.

GUARAPUAVA. Lei n 2.597, de 2 de dezembro de 2016. Institui o Plano Municipal de Políticas Públicas para Mulheres de Guarapuava (PMPPM). Guarapuava: Prefeitura Municipal de Guarapuava, 2016. Disponivel em: https://bit.ly/37YtK94. Acesso em: 25 jun. 2020.

HIRATA, H.; KERGOAT, D. A classe operária tem dois sexos. Revista Estudos Feministas, Florianópolis, v. 2, n. 3, p. 93-100, 1994.

JABLONSKI, B. A divisão das tarefas domésticas entre homens e mulheres no cotidiano do casamento. Psicologia: Ciência e Profissão, Brasilia, DF, v. 30, n. 2, p. 262-275, 2010.

KERGOAT, D. Divisão sexual do trabalho e relações sociais de sexo. Tradução de Vivian Aranha Saboia. In: HIRATA, H.; LABORIE, F.; LE DOARÉ, H.; SENOTIER, D. (org.). Dicionário crítico do feminismo. São Paulo: Editora Unesp, 2009. p. 67-75.

LIMA, K. F.; OLIVEIRA, G. A. A feminização da pobreza. In: SIMPÓSIO INTERNACIONAL INTERDISCIPLINAR EM CIÊNCIAS SOCIAIS APLICADAS, 2., 2017, Ponta Grossa. Anais [...]. Ponta Grossa: Universidade Estadual de Ponta Grossa, 2017. p.1-8. Disponivel em: https://bit.ly/2A3HEub. Acesso em: 25 jun. 2020.

MARCONDES, M. M.; PINHEIRO, L.; QUEIROZ, C.; QUERINO, A. C.; VALVERDE, D. (org.). Dossiê mulheres negras: retrato das condições de vida das mulheres negras no Brasil. Brasilia, DF: Ipea, 2013. Disponivel em: https:// bit.ly/2NqByqR. Acesso em: 25 jun. 2020.

MARTINELLI, M. L. (org.). Pesquisa qualitativa: um instigante desafio. São Paulo: Editora Veras, 1999.

MARX, K. O capital: crítica da economia política. Tradução de Regis Barboza e Flávio R. Kothe. São Paulo: Abril Cultural, 1984. v. 1, t. 2. (Coleção Os Economistas). 
PEREIRA, A. B.; RODRIGUES, E.; GUILHERME, R. C. Ações afirmativas: política de cotas raciais para o ingresso nas universidades públicas. Textos \& Contextos, Porto Alegre, v. 9, n. 2, p. 244-250, 2010.

SAFFIOTI, H. I. B. O poder do macho. São Paulo: Moderna, 1987.

SAFFIOTI, H. I. B. Violência doméstica ou a lógica do galinheiro. In: KUPSTAS, M. (org.). Violência em debate. São Paulo: Moderna, 1997. p. 39-57.

SAFFIOTI, H. I. B. Gênero, patriarcado, violência. São Paulo: Fundação Perseu Abramo, 2004.

SARTI, C. A. Familias enredadas. In: ACOSTA, A. R.; VITALE, M. A. F. (org.). Família: redes, laços e políticas públicas. São Paulo: Instituto de Estudos Especiais da Pontifícia Universidade Católica de São Paulo, 2002. p. 21-36.

SILVA, I. M. F. Questão social e o serviço social no Brasil: fundamentos sóciohistóricos. 2. ed. Campinas: Papel Social; Cuiabá: EdUFMT, 2014.

WAISELFISZ, J. J. Mapa da violência 2018: homicídio de mulheres no Brasil. Brasilia, DF: Flacso Brasil, 2018.

Recebido em outubro de 2019.

Aprovado em dezembro de 2019. 